Der Technikdiskurs

in der Hitler-Stalin-Ära 


\section{Der Technikdiskurs}

in der Hitler-Stalin-Ära

Herausgegeben von Wolfgang Emmerich und Carl Wege

Verlag J. B. Metzler

Stuttgart · Weimar 
Die Deutsche Bibliothek - CIP-Einheitsaufnahme

Der Technikdiskurs in der Hitler-Stalin-Ära / hrsg. von

Wolfgang Emmerich und Carl Wege. - Stuttgart ; Weimar : Metzler, 1995

ISBN 978-3-476-01307-1

NE: Emmerich, Wolfgang [Hrsg.]

ISBN 978-3-476-01307-1

ISBN 978-3-476-03599-8 (eBook)

DOI 10.1007/978-3-476-03599-8

Dieses Werk einschließlich aller seiner Teile ist urheberrechtlich geschützt. Jede Verwertung außerhalb der engen Grenzen des Urheberrechtsgesetzes ist ohne Zustimmung des Verlages unzulässig und strafbar. Das gilt insbesondere für Vervielfältigungen, Ubersetzungen, Mikroverfilmungen und die Einspeicherung und Verarbeitung in elektronischen Systemen.

(C) 1995 Springer-Verlag GmbH Deutschland

Ursprünglich erschienen bei J. B. Metzlersche Verlagsbuchhandlung und Carl Ernst

Poeschel Verlag GmbH in Stuttgart 1995 


\section{Inhaltsverzeichnis}

Einleitung $\ldots \ldots \ldots \ldots \ldots \ldots \ldots$

$\star$

Helmut Lethen: Die elektrische Flosse Leviathans.

Ernst Jüngers Elektrizität . . . . . . . . . . . . . . . 15

Ulrike Baureithel: Zivilisatorische Landnahmen. Technikdiskurs und Männeridentität in Publizistik und Literatur der zwanziger Jahre . . . . . . . . . . . . . 28

Gudrun Kohn-Waechter: Ersatzwelt, totale Herrschaft, Risikolust - Elemente eines modernen Technikdiskurses am Beispiel von John Desmond Bernal . . . . . . . . . .

Jeffrey Herf: Der nationalsozialistische Technikdiskurs. Die deutschen Eigenheiten des reaktionären Modernismus . . . . . . . . . . . . . . . .

Anson Rabinbach: Nationalsozialismus und Moderne.

Zur Technik-Interpretation im Dritten Reich . . . . . . . . 94

Friedrich Kittler: Auto Bahnen . . . . . . . . . . . . . 114

Erhard Schütz: Faszination der blaßgrauen Bänder. Zur »organischen« Technik der Reichsautobahn . . . . . 123

David Milde: Lernen von den Eskimos.

Der Weltfahrer Colin Roß zwischen Moderne und Nationalsozialismus . . . . . . . . . . . . . . . . 146

$\star$

Frank Trommler: Amerikas Rolle im Technikverständnis der Diktaturen . . . . . . . . . . . . . . . . . . . 159 
VI Inhaltsverzeichnis

Klaus Städtke: Wandel im Technikbewußtsein.

Zur Geschichte eines sowjetischen Ideologems . . . . . 175

$\star$

Anneli Hartmann/Wolfram Eggeling: „Das zweitrangige

Deutschland « - Folgen des sowjetischen Technik-

und Wissenschaftsmonopols für die SBZ und die frühe

DDR ...................... 189

Sigrid Meuschel: Symbiose von Technik und Gemeinschaft. Die Reformideologie der SED in den sechziger Jahren . . . . . . . . . . . . . . . . . . 203

Wolfgang Emmerich: „Die Technik und die Kehre«. Affirmation, Protest und Regression im literarischen Technikdiskurs der DDR . . . . . . . . . . . . . 23

Carl Wege: Zum Verhältnis von Filmkunst und Schriftkultur im »realen Sozialismus« der DDR . . . . . . . . . . 255

$\star$

Ralf Schnell: Tradition und Modernisierung -

Das Modell Japan . . . . . . . . . . . . . . . . . . . . 269 